\title{
Hybrid Configurations of Leadership in Higher Education Employer Engagement
}

\author{
Richard Bolden ${ }^{1}$ and Georgy Petrov ${ }^{2}$ \\ ${ }^{1}$ University of the West of England, Bristol, UK, Richard.Bolden@uwe.ac.uk \\ ${ }^{2}$ Kingston University Business School, UK, G.Petrov@kingston.ac.uk
}

Paper accepted for publication in Journal of Higher Education Policy and Management, 36(1), February 2014

\begin{abstract}
Recent literature has emphasised the distributed nature of leadership in higher education and the multitude of actors and factors that contribute towards organisational outcomes. Gronn $(2009,2011)$ suggests, however, that rather than using such evidence to provide broad, normative accounts of leadership practice, greater attention should be directed to mapping the 'hybrid configurations' through which leadership practice emerges. This paper responds to this call through an analysis of employer engagement activities in UK higher education. Using a qualitative case study approach it illustrates the complex, interdependent, and contested, nature of leadership practice in cross-boundary environments. The paper concludes by suggesting how a hybrid perspective may enhance leadership theory and practice in tertiary education.
\end{abstract}

\section{Keywords}

Distributed leadership, hybrid configurations, employer engagement, boundary spanning, shared leadership, emergent leadership 


\section{Introduction}

Recent years have seen growing recognition of the relational and collective nature of leadership - portraying it as a shared, group process rather than a quality or characteristic of the 'leader' (Uhl-Bien, 2006). For a concept developed just over a decade ago 'distributed leadership' (Gronn, 2000, 2002) has been a particular success story and is now widely advocated as the preferred approach to leadership in many sectors and organisations (see Bolden, 2011 for a review). From a distributed perspective, leadership is considered to be 'an emergent property of a group or network of interacting individuals' (Woods, Bennett, Harvey \& Wise, 2004, p. 441) in which everyone has a part to play. A distributed perspective draws attention to the importance of context in determining who leads at a given time - suggesting that concern and expertise are equally as important as seniority (Spillane, Halverson \& Diamond, 2004).

The emphasis on inclusivity and collegiality, along with a strong track record of research in schools and colleges, has made distributed leadership an obvious choice for leadership research, development and practice within universities. Indeed, in a recent special issue of Higher Education Research and Development on 'Leading the Academy: defining the future of leadership in higher education' approximately ninety percent of submissions were on some aspect of distributed leadership (Macfarlane, 2014).

Whilst the shift to a more systemic and participative perspective on leadership within higher education is to be applauded, it is not without its difficulties and limitations. As recent work in this journal has illustrated (e.g. Murphy \& Curtis, 2013; Pitcher, 2013; White, Carvalho \& Riordan, 2011; Winter, 2009) the growth of the managerial agenda within universities puts pressure on academics, administrators, managers and a range of other stakeholders to work together in ways that have not previously been required. In such situations, leader-follower dynamics are not straightforward and the notion that everyone can contribute towards leadership may be seen as simple rhetoric - quite at odds with lived experience (Bolden, Gosling \& Petrov, 2009; Knights \& Clarke, 2013). Some authors go further, to suggest that the discourse of 'distributed leadership' may itself have a performative effect on how people conceive of and engage with organisational priorities (Gosling, Bolden \& 
Petrov, 2009; Hall, Gunter \& Bragg, 2011). Lumby (2013) deploys Lukes' (1974) framework of power to argue that distributed leadership has become a disciplinary practice that controls and regulates thoughts and behaviour, somewhat ironically maintaining rather than challenging the status quo.

'There is, arguably, no such thing as an apolitical theory in education. Ignoring politics can be interpreted as a political act as much as overt engagement. In its avoidance of issues of power, distributed leadership is a profoundly political phenomenon, replete with the uses and abuses of power.' (ibid, p.12)

In this paper we move beyond ideological accounts of leadership to consider the ways in which authority, influence and power are actually 'distributed' between individuals, groups and organisations. In order to do so, we engage with Gronn's $(2009,2011)$ notion of 'hybrid configurations' of leadership. For Gronn, the idea of leadership configuration - 'a pattern or an arrangement of practice' (Gronn, 2009, p. 383) - carries two major implications for leadership scholars. Firstly, rather than seeking to describe particular styles of leadership in isolation, researchers would be advised to identify and map the multiple hybrid forms of leadership that occur within a particular context longitudinally over time. Secondly, 'a corollary of this strategy of mapping or contouring practice is to subvert the rationale and validity of what might be termed normative leadership advocacy' (ibid, p. 391). To this extent, he suggests a shift from accounts of how leadership should be enacted (often associated with labels such as 'distributed', 'transformational' or 'authentic') to empirical accounts of how leadership is accomplished through the interaction of vertical, horizontal, emergent and other forms of social influence.

The empirical evidence for this paper is derived from a study of employer engagement in UK universities (Bolden, Connor, Duquemin, Hirsh, \& Petrov, 2009). We present two case studies in order to illustrate how leadership practice emerged through the interplay of a range of actors and processes over time. Whilst HEemployer engagement is often characterised as a simple relationship between a university and an employer the reality is often far more complex and characterised by inter-organisational networks (Muller-Seitz, 2012) comprising a diverse range of stakeholders. This is a particularly interesting environment in which to explore 
hybrid configurations of leadership because of the need for individuals and groups to coordinate activities across professional and organisational boundaries. Universities, further education colleges, policy bodies and employers come from very different backgrounds, with different norms and expectations about how things get done. The leadership challenges here are not simply about enabling people to accomplish tasks but of bridging cultures and identities to create a sense of shared direction, alignment and commitment (Ernst \& Chrobot-Mason, 2010; Hogg, Rast \& Van Knippenberg, 2012).

The cases have been chosen as examples of different modes of engagement, from a relatively emergent case of an individual academic developing an employer relationship (Case 1) to a more strategic initiative in which an HE consortium was established to develop a suite of programmes for a large regional employer (Case 2). In each case we focus on the role played by various actors and how they interface with organisational systems and processes. Through this, we illustrate the contribution of people in different roles and the manner in which leadership practice is distributed within and across organisational boundaries. This work contributes to the aim of the special issue by shedding light on the nature of vertical, horizontal and emergent leadership in tertiary education and to the leadership and organisation studies literature by extending research on leadership beyond organisation and role boundaries.

\section{Case 1: English for engineers}

This case explores an initiative that involved direct engagement between a university and two employers. The initiative was established and led by a single academic who built on existing relationships with two major engineering companies to deliver a training programme for engineers to improve their proposal-writing skills when responding to tenders. The arrangement with the first company was non-financial: she provided courses to engineers in exchange for use of the company facilities, and the opportunity to work alongside the engineers, which supported her academic research. However, courses at the second company were financially based, with the employer paying commercial rates. This case can be considered an example of emergent informal leadership as the academic initiated, led and delivered the project herself. 
Despite the academic's entrepreneurial approach, her lack of formal power and authority posed a number of challenges when engaging with internal stakeholders. This was particularly evident in relation to how income from the second intervention was handled and, despite a verbal agreement that funds would be ringfenced in order to recruit an additional staff member, that promise was not honoured:

'Before I started I went round and talked to people [in finance] and I said: "I'll do this work but I need assurance that the money will be kept safe"... I got promises, the money came rolling in, but when I wanted to employ somebody for this semester, I found that the money had disappeared. Big black hole! The money had gone!' (Case 1, Interview 1)

Without access to resources (that she had brought to the institution) to fund extra staff the academic anticipated the need to cancel planned activities for the company, being unable to carry the additional workload herself. Eventually, she navigated complex organisational structures and processes by utilising her social networks and only after the involvement of the university Business Development Officer was this issue resolved:

'I went to the company and said: "I don't think, I am going to be available". The company called me for a special meeting to talk to me. Our Business Development Officer came with me and I don't know what she did but she found money. So, I used that to bring in a member of staff. I wanted someone for a full-time, short-term contract... It was so difficult getting the agreement. We had to involve our personnel department. There were arguments, I can't tell you, it was so difficult.' (Case 1 Interview 1)

The situation the academic had found herself in illustrates differing levels of agency afforded to the various actors by virtue of their privileged access to resources and relationships as well as the impact of misaligned of institutional systems and processes. These tensions were also recognised by senior members of the institution, as indicated in the following quotes from the Principal and Deputy Principal:

'There is a somewhat inevitable tension between the centre and departments which can only be ameliorated through coordinating, championing and disseminating information.' (Case 1, Interview 3) 
'We need to recognise and reward academic staff for their contributions and to find ways of building and embedding capacity... The internal systems need to be right in order to support and sustain [employer engagement] activity... You can’t just depend on good will.' (Case 1, Interview 4)

In this particular situation the outcome was facilitated by the Business Development Officer who played an important role in supporting the academic's interactions with key stakeholders and acting as a broker with administrative partners.

Another challenge concerned a cultural gap between the way(s) in which this initiative was perceived by Human Resource (HR) departments in both companies and the university. The following quote from the academic illustrates this point:

'HR departments wanted me to do training... they seem to think if I come up with ten bullet points, you know what I am talking about, and I am interested in a different approach... the HR people were very nice but they could tell that I was possibly going to muscle in as it were'. (Case 1, Interview 1)

The academic had to be sensitive when dealing with issues across organisational boundaries in order not to upset relationships and, in the absence of any formal power, had to depend on her skills of influence and persuasion. As her confidence grew and she got to know course participants she began building relationships with them directly and was able to bypass the HR departments, although remaining aware of the need to tread carefully in order to retain institutional and company support.

This direct model of engagement, where there was a one-to-one relationship between the university and employer, was the most common found in our study. However, even in this apparently simple partnership the outcome is dependent on a wide range of people and processes. In this case it is evident that the academic's attempts to lead and be entrepreneurial were constrained by unresponsive university processes. In other words, emergent leadership and structural configurations were not mutually supportive and given the difficulties securing organisational support the academic moved over time from an aspiration to grow this activity and bring in additional staff to focussing simply on what she could achieve herself and 'buying time out' from other commitments. Whilst the leadership configuration was not wholly dysfunctional, the poor alignment between the entrepreneurial approach of the 
academic and institutional systems and processes made it difficult to sustain and, in the end, the academic left her institution and pursued the initiative independently.

\section{Case 2: Developing Foundation Degrees for a regional employer}

This case considers the development of a series of vocational 'Foundation Degrees' for a large regional employer. It is interesting as it illustrates a more complex relationship between actors and organisations than is reported in Case 1 and one more explicitly characterised by imbalances of power and differences of culture. In this context, we suggest, leadership is highly contested and political.

The trigger for the development of this initiative arguably occurred when the Chief Executive Officer (CEO) of the employer organisation made a public commitment to skills development in his company. This commitment was underpinned by plans to develop a training academy that would draw on both inhouse expertise as well as external providers offering training at all levels of tertiary education. In planning for this, the company put out a call for potential partners to attend an open day and submit a formal proposal. The bidding process was won by a local Further Education college as the lead academic partner in helping the company develop its academy.

Later the college found out about a government funding initiative and realised that it was a great opportunity to secure funds for developing the Foundation Degree aspects of the curriculum, drawing on the specialist expertise of a number of universities. In developing the bid the college established a partnership with a nearby research-intensive university (referred to as University A), which itself was looking to establish a strategic relationship with the company and with which the company also sought to develop links given its academic reputation. In addition two other universities, with specialist areas of expertise, were later included in the bid, with each of the three university partners now charged with the development of a different Foundation Degree. The College, under the guidance of the Vice Principal, coordinated the development and submission of the funding proposal, with contributions from the three university partners.

Whilst the initial bid was unsuccessful a subsequent submission that articulated a closer link between the three Foundation Degrees on a reduced budget, 
and in which University A was accorded the more prominent strategic role as budget holder (but with the college still as lead academic partner), did receive funding. At an organisational level, it is possible to trace how a strategic announcement by an employer to upskill its employees paved the way for the development of a network of academic partners to deliver, administer and even secure funding for a suite of Foundation Degrees. Could this be considered as a case of shared or distributed leadership? Perhaps, but a closer look at the role of key individuals and groups may give a more nuanced picture and reveal that locating the 'leadership' of this initiative is not so straightforward.

Whilst the company CEO could be regarded as the instigator, senior leaders at the college also played a key role in establishing and mobilising the network. In describing how the college coordinated the funding bid, one interviewee said the following:

'The fact is, senior leadership [were] prepared to put in huge amounts of manhours, so actually there has been quite a cost to the College in that sense, because if you take a Vice-Principal's salary every year and work out how much time they've spent at all the steering groups, all the meetings, all the emails... You know, so it is quite a considerable amount of time and energy and effort and at a high level and at high cost.' (Case 2, Interview 2)

Senior leaders at University A also played an important role in cementing the relationship through the desired affiliation between the university and the company and the gravitas it added to the funding bid. In this instance there are clearly grounds for acknowledging the contribution of formal leaders. However, in moving from the proposal to the delivery there has been a strong emphasis on the development of a more participative, team-based, approach.

The college appointed a Training Partnership Manager who would drive the partnership forward and have overall responsibility for all levels of training connected with the academy. In addition, University A appointed an HE Project Manager, who played a key leadership role specifically for the three Foundation Degrees addressing quality assurance, validation and accreditation procedures and acting as the interface between the company, partner universities and college as far as HE aspects were 
concerned. An early task for this manager was to establish the cross-organisation steering group for Foundation Degrees with representation from a wide range of organisations that would co-lead the project. It was set up with the aim of providing an important ambassadorial role and demonstrating commitment of the various partners. Even though it had taken quite long time to get 'buy-in' from all the partners what the HE Project Manager aimed to achieve was a sense of partners working together:

'We're breaking a new ground and [the steering group] is the only place where all the parts come together and, therefore, it has a very important role to play... Certainly, there's instances where things are kind of falling in the holes, and it's very much a case of working with those people to, in some cases redefine new ways of doing things, or in other cases just to occasionally keep nudging, and nudging a bit harder, and nudging a bit harder...' (Case 2, Interview 1)

Although the college led and won the bid to work with the company, there was some disagreement over who led and managed the implementation stage of the project:

'The college believe that they lead the project and their interpretation of the partnership is [the company] is the customer, and it's college's project and [the college] should be having more influence over such and such... That's not the perspective of other partners in terms of who the client is and whose project it is.' (Case 2, Interview 1)

Each partner involved in the project had its own agenda and the HE Project Manager saw it as his task to support each organisation to gain something of value from its involvement in the project and to create the environment for informal leadership to emerge for different stages and aspects of the initiative.

In addition to the steering group, a curriculum design group with three separate curriculum development subgroups for each Foundation Degree with input from the company were formed. The different agendas became apparent when the decision was made to postpone delivery of the University A validated Foundation Degree and, although the company agreed, the college strongly resisted the delay. The college's resistance was said by one interviewee to be due to the importance they 
placed on demonstrating their efficiency in order to maintain a positive relationship with the company. For University A, however, a prime concern was maintaining its reputation for quality even if this meant delaying the start date. So, the success or failure of this initiative was largely dependent on Partnership and Project Managers building a sense of shared commitment, direction and alignment across the various partners, their different agendas and interests, managing potential inconsistencies (e.g. reputation and branding) and trying to make sure there was a win-win outcome for all involved.

All of this occurred in a complex and changing landscape. As well as the challenge of bringing together a large number of partners, another layer of complexity stemmed from each university academic department involved in the project having its own mode and patterns of communication and culture. In addition, the two managers had to liaise with different central functions at three universities, the college and the company to accomplish success for the initiative. Yet another dimension of complexity as well as uncertainty was caused from structural changes, which were taking place in one of the partner organisations whilst the project was underway.

\section{Discussion}

Together these two cases indicate a variety of leadership roles, functions and processes that shift and evolve over time. Traditional approaches to researching and theorising leadership, that focus on the characteristics and behaviours of one or more 'leaders' in order to determine predictors of effective leadership, are clearly inadequate to capture the complexities of situations such as these. Similarly, simply describing these as examples of 'distributed leadership' obscures almost as much as it reveals. Yes, in both cases a range of 'leadership' actors can be identified; and 'yes' emergent, horizontal and shared leadership can be identified alongside hierarchical/formal leadership. However, it is the interaction between these forms and manifestations of leadership that produce the observed effects rather than any of them in isolation.

Case 1, for example, shows how the potential for an individual to develop effective employer-focussed initiatives is linked to his/her ability to secure and retain access to resources. In this case institutional systems and processes were largely 
misaligned with the entrepreneurial approach of the academic and severely hampered her capacity to establish a sustainable way of working. Much time and effort was spent navigating organisational bureaucracies and finding ways of (re)framing the initiative so that its value could be recognised by Finance and HR departments of both organisations (whilst struggling to ensure that it also met the educational needs of participants and the academic's own scholarship). The Business Development Officer played an important role in supporting the academic's interactions with key stakeholders but the ultimate outcome was disengagement and eventual departure from the university, despite the espoused intent of senior university leaders to encourage and grow this kind of activity.

Case 2 highlights the complex relationship between formal and informal leadership and the politics of collaboration between institutions. It demonstrates that whilst the success of strategic initiatives may often be attributed to the vision and support of senior level leaders they are only accomplished thanks to emergent, informal and shared leadership by people on the ground. In the case of initiatives, such as this, that require direction, alignment and commitment across organisational boundaries, a range of different leadership roles and functions are required over time (Ernst \& Chrobot-Mason, 2010). These include people or groups who act as ambassadors or champions; who take ownership of and drive forward different stages/aspects of the initiative; who coordinate and liaise between constituents 'nudging' when required; and who help shape or (re)frame narratives that enable boundary spanning to occur. In this case political and cultural differences between institutions also impacted on the nature and forms of leadership required in order to achieve a successful outcome. University A, for example, used their status and reputation to secure their position in the partnership, whilst the college needed to work much harder to ensure they remained involved (despite having done much of the ground work in establishing the consortium and identifying funding). Throughout this initiative there were differing expectations and aspirations of the various stakeholders that needed to be carefully balanced in order to keep things on track. In this ambiguous and contested environment the Partnership Manager, and at times others, played a key role in 'translating' between partners and 'nudging' things forward. Without this on-going coordination and liaison it is likely an initiative such as this would have lost momentum and the partnership may have crumbled. Whilst such 
roles and functions are rarely particularly high profile they are essential features of the leadership landscape and key to understanding the causes of success and failure.

To appreciate the nature of leadership in and of both these initiatives it is suggested that a holistic view is required in order to recognise what facilitates and inhibits the achievement of leadership outcomes. As Drath, McCauley, Palus, Van Velsor, O'Connor, \& McGuire (2008) suggest, the language of 'leaders', 'followers' and 'shared goals' is inadequate in such situations as any or all of those categories may remain ambiguous or contested. Describing these initiatives as examples of 'distributed' or 'shared' leadership is similarly inadequate as it fails to explain what is distributed or shared, to whom, how, where, when and why. Simply advocating a distributed or shared approach to leadership is unlikely to have a positive impact in the absence of a clear sense of what constitutes a more or less effective configuration of leadership practice and pattern of social influence.

In an analysis of the ways in which leadership is distributed within universities Bolden, Petrov \& Gosling (2008) identified five dimensions of leadership practice (personal, social, structural, contextual and developmental) occurring over a number of levels (individual, group and organisational). The current paper illustrates a need to extend this framework to include an inter-organisational level to account for multiinstitutional contexts. It is also suggests that it may be helpful to further differentiate a number of the dimensions - in particular 'context' which incorporates aspects of discourse, power and politics. Through this detailed mapping it may be possible to more accurately identify the components of an effective leadership configuration.

Whilst, given its complexity, such an approach is unlikely to be embraced widely within organisations it may offer a useful means for analysing particular examples in order to draw out lessons on what did and did not work in order to inform the design of future initiatives. Hence, on this basis, one may be inclined to ask questions such as 'who were the main actors', 'how did they engage with one another', 'what structures and processes supported this', 'how did the organisational context (including dynamics of power, politics and language) impact on the leadership process', and 'how did these dimensions shift and change over time'? Such questions encourage us to look beyond the usual suspects and to engage with a wider range of constituents. 
However, whilst we endorse a more systemic approach to the study of leadership we hold only limited expectations about its potential to identify enduring principles of effective leadership. If, as several authors now suggest, leadership is best understood as a socially constructed concept (Fairhust \& Grant, 2010) then there is no underlying essence to be found; no enduring 'configuration' to be captured or implemented. Instead, the value of such an approach may be in sensitising us to the questions we need to ask; the kinds of practice we seek to develop; and a means for assessing the causes of success and/or failure.

\section{Conclusions}

When thinking about distributed leadership in higher education we are reminded of the quote from Bennis \& Nanus (1985, p. 19), that 'leadership is like the Abominable Snowman, whose footprints are everywhere but who is nowhere to be seen'. There may be brief glimpses of the kind of 'conjoint agency' described by Gronn (2002) but these are elusive and hard to document. The consequence is that despite the best efforts of many people working in this field there is a tendency to resort to the familiar 'tripod' of leaders, followers and shared goals (Bennis, 2007 cited in Drath et al., 2008, p. 635) when explaining how leadership is accomplished. The problem, of course, is that whilst the tripod may be adequate for describing certain manifestations of leadership practice it fails to capture the complexities of how it occurs in ambiguous and contested contexts over time.

In this paper we have used two case studies to illustrate the complex hybrid configuration of actors and factors that contribute towards success and failure in university-employer engagement. Whilst leadership in such contexts remains an inherently political process and 'hybrid' accounts of leadership are unlikely to resolve inequalities of power and influence they may, at least, equip us with a more thorough appreciation of the micro-politics of organisational life and a means for placing recognition, rewards and resources where they are most deserved.

\section{References}

Bennis, W. (2007). The challenges of leadership in the modern world: an introduction to the special issue, American Psychologist, 62(1), 2-5. 
Bennis, W. \& Nanus, B. (1985). Leaders: The strategies for taking charge. New York: Harper \& Row.

Bolden, R. (2011). Distributed leadership in organizations: a review of theory and research, International Journal of Management Reviews, 13(3), 251-269.

Bolden, R., Connor, H., Duquemin, A., Hirsh, W. \& Petrov, G. (2009). Employer Engagement with Higher Education: Defining, Sustaining and Supporting Higher Skills Provision. A South West Higher Skills Project Research Report: University of Exeter and CIHE.

Bolden, R., Petrov, G. \& Gosling, J. (2009). Distributed leadership in higher education: rhetoric and reality, Educational Management, Administration and Leadership, 37(2), 257-277.

Bolden, R., Petrov, G. \& Gosling, J. (2008). Tensions in higher education leadership: towards a multi-level model of leadership practice, Higher Education Quarterly, 62(4), 358-376.

Drath, W. H., McCauley, C. D., Palus, C. J., Van Velsor, E., O'Connor, P. M. G. \& McGuire, J. B. (2008). Direction, alignment, commitment: Toward a more integrative ontology of leadership, The Leadership Quarterly, 19(6), 635-653.

Ernst, C. \& Chrobot-Mason, D. (2010). Boundary Spanning Leadership: Six Practices for Solving Problems, Driving Innovation, and Transforming Organizations. McGraw Hill, New York.

Fairhurst, G.T. \& Grant, D. (2010) The social construction of leadership: a sailing guide, Management Communication Quarterly, 24(2) 171-210.

Gosling, J., Bolden, R. \& Petrov, G. (2009). Distributed leadership in higher education: What does it accomplish? Leadership, 5(3), 299-310.

Gronn, P. (2000). Distributed properties: a new architecture for leadership, Educational Management \& Administration, 28(3), 317-338.

Gronn, P. (2002). Distributed leadership as a unit of analysis, Leadership Quarterly, $13,423-451$. 
Gronn, P. (2009). Leadership configurations, Leadership, 5, 381-394.

Gronn, P. (2011). 'Hybrid configurations of leadership' in A. Bryman, D. Collinson, K. Grint, B. Jackson \& M. Uhl-Bien (eds) The Sage Handbook of Leadership, pp. 437-454. London: Sage.

Hall, D., Gunter H.M. \& Bragg, J. (2011). The discursive performance of leadership in schools, Management in Education, 25 (1), 32-36.

Hogg, M.A., Rast III, D.E., \& Van Knippenberg, D. (2012) Intergroup leadership in organizations: leading across group and organizational boundaries, Academy of Management Review, 37(2), 232-255.

Knights, D. \& Clarke, C.A. (2013) It's a bittersweet symphony, this life: fragile academic selves and insecure identities at work, Organization Studies, Online First, 13/11/13.

Lukes, S. (1974). Power: A radical view. London: Macmillan.

Lumby, J. (2013). Distributed leadership: the uses and abuses of power, Educational Management Administration \& Leadership, Online First, 18/07/13.

Macfarlane, B. (2014). Challenging leaderism. Higher Education Research \& Development, 33(1), 1-4.

Muller-Seitz, G. (2012). Leadership in interorganizational networks: a literature review and suggestions for future research, International Journal of Management Reviews, 14, 428-443.

Murphy, M. \& Curtis, W. (2013). The micro-politics of micro-leadership: exploring the role of programme leader in English universities, Journal of Higher Education Policy \& Management, 35(1), 34-44.

Pitcher, G.S. (2013). Managing the tensions between maintaining academic standards and the commercial imperative in a UK private sector higher education institution, Journal of Higher Education Policy \& Management, 35(4), 421431. 
Spillane, J.P., Halverson, R. \& Diamond, J.B. (2004). Towards a theory of leadership practice: a distributed perspective, Journal of Curriculum Studies 36(1), 3-34.

Uhl-Bien, M. (2006). Relational leadership theory: exploring the social processes of leadership and organizing, The Leadership Quarterly, 17, 654-676.

White, K., Carvalho, T. \& Riordan, S. (2011). Gender, power and managerialism in universities, Journal of Higher Education Policy \& Management, 33(2), 179188.

Winter, R. (2009) Academic manager or managed academic? Academic identity schisms in higher education, Journal of Higher Education Policy \& Management, 31(2), 121-131.

Woods, P.A., Bennett, N., Harvey, J.A. \& Wise, C. (2004) Variabilities and dualities in distributed leadership: findings from a systematic literature review, Educational Management Administration \& Leadership, 32(4), 439-457. 